\title{
Iniquidades em saúde no Brasil sob as lentes da sociedade civil
}

PELLEGRINI FILHO, A. (Org.).

\section{As causas sociais das iniquidades em saúde no Brasil.}

Comissão Nacional sobre Determinantes Sociais da Saúde.

Rio de Janeiro: Editora FIOCRUZ, 2008. 215p.

\section{| ${ }^{1}$ Maria do Socorro Quirino Escoda I}

1 Nutricionista; sanitarista; epidemióloga; mestre e doutora em Sociologia do Desenvolvimento. Professora pesquisadora, Universidade Federal do Rio Grande do Norte (UFRN). Endereço eletrônico: maria.escoda@uol.com.br

A obra em resenha é produto final da Comissão Nacional Sobre Determinantes Sociais da Saúde (CNDSS) e texto exemplar desta temática. A CNDSS foi criada em 2005 pela Organização Mundial da Saúde (OMS), para promover o debate e "uma tomada de consciência sobre a importância dos determinantes sociais sobre a situação de saúde de indivíduos e populações, e sobre a necessidade de combater as iniquidades em saúde por eles geradas”. Reuniu 16 personalidades da sociedade civil, dentre artistas, cientistas e empresários, com o objetivo de "realizar panorama da situação e das iniquidades em saúde, propor políticas, programas e intervenções”.

Consta no prefácio a relevância dessa obra para as áreas de conhecimento e setores de intervenção em saúde, e a natureza estrutural das desigualdades sociais como "geradas pela ação humana e por ela devem ser transformadas". $\mathrm{O}$ constructo de evidências, análises e recomendações, em sintonia com os conteúdos e arranjos editoriais, confere cumprimento de objetivo da comissão e primor de arte final. A estratégia metodológica adotada para a formulação das análises e proposições (o modelo de determinação social da saúde, de Dahigren e Whitehead) tem nuance funcionalista, em função das dimensões e disposição das categorias analíticas utilizadas.

Este modelo gráfico é arquétipo da teoria da multicausalidade dos processos que enredam a saúde e a doença, por conjugar com igual peso os determinantes 
de desigualdades sociais de ordem estrutural e os de ordem conjuntural, com abstração de determinantes sociais considerados de maior peso na correlação dos processos geradores dessas formas de iniquidade. Os autores, entretanto, consideram esta opção metodológica como de maior aproximação à realidade avaliada. $\mathrm{Na}$ figura ilustrativa, estão denominadas como dimensões distais as condições socioeconômicas, culturais e ambientais gerais: condições de vida e de trabalho, redes sociais e comunitárias. Como dimensóes proximais, o estilo de vida dos indivíduos: idade, sexo e fatores hereditários.

Nas seções descritoras da temática central, o leitor se encontra com o feliz escape de definiçõos formais e assépticas que o colocam como espectador do sempre difícil processo de definição, de síntese do problema central, de hipóteses, teses e teorias. A descrição dos conteúdos se desenvolve com boa sistematização em quadro analítico, que flui na sutileza da paciência didática e da ponderação inclusive de que essa produção não pretende esgotar o assunto. A trajetória de coerência das descriçôes efetuadas sobre as atividades, compromissos finais da CNDSS e como modelo analítico adotado se faz com distinção literária.

A segunda seção do livro revela a natureza dialética da análise sobre a situação de saúde, com o entrelace de teses da terceira seção, que elenca as recomendações sobre intervençôes de políticas e programas. A evidência mais contundente dessa situação se manifesta nas tendências da evolução demográfica, social e econômica (em gênero, longevidade e empoderamento), peculiarmente na inversão de assentamento do perfil populacional, no sentido rural, urbano e regional. Desses indicadores, destacam-se a forte redução ocorrida na taxa de fecundidade, que era de 6,3 filhos por mulher em 1960, para 2,3 em 2000. A inversão rural/ urbana se registra em $81 \%$ dos domicílios permanentes na área, e a inversão das migrações inter-regionais, anteriormente em Norte-Nordeste, para Sul-Sudeste - movimentos que nas últimas décadas estão explicados pelas transformações econômicas sobre a situação social.

Nas análises efetuadas, as tendências demográficas do "socialmente determinado" no perfil epidemiológico da população estão correlacionadas pela estratificação das condições e estilos de vida - como ponto de partida, de convergência e norteamento das intervenções programáticas de reorganização da assistência que impactem na saúde e na reversão de iniquidades. Epistemologicamente, as desigualdades sociais e as iniquidades em saúde estão 
lastreadas por bases empíricas de estudos nacionais, dos Censos (1960, 2000), estudos posteriores como a PNAD (2004) e outros de igual expressão.

Nessa série histórica, está demarcado que, da população economicamente ativa, $55 \%$ se dedicaram à agricultura, em contrapartida aos $21 \%$ encontrados em 2000. O desenvolvimento é considerado desigual por região e por classe, e as brechas sociais mais profundas desse processo situam-se, pela ordem, em Nordeste, Norte e Centro-Oeste. Os autores apontam a insuficiência na geração de empregos na indústria, comércio e serviços, em proporção geométrica na oferta em relação à pressão da demanda produzida pelos êxodos. Esses movimentos, oriundos do desmantelamento da estrutura produtiva, elevada concentração das terras agriculturáveis, com precarização das relações de trabalho, reduziram o emprego na agricultura de 55\% para $19 \%$.

Esses dados reafirmam o peso da agricultura como bem essencial da economia brasileira, da estreita correlação da posse e do tamanho da terra com as condições materiais de vida, assim como da situação alimentar e nutricional, com a otimização da renda sobre a saúde, em todos os estágios experimentados pelo desenvolvimento nacional. $\mathrm{Na}$ análise efetuada, estão ausentes dados de desigualdades sociais gerados pela concentração da terra, renda do capital, acesso à justiça e segurança pública, apontados como inquietantes nos estudos de insatisfação social atuais. Igualmente ausentes nesse trabalho estão as formas de assistência no sistema público, resultantes dos arranjos organizacionais (da atenção básica, que privilegia por critérios biológicos os socialmente horizontais), produtores das referidas iniquidades.

$\mathrm{Na}$ estratificação social, encontram-se bem demarcados os impactos das condições de ambiente, habitação, saneamento, emprego, trabalho, renda, alimentação, educação, informação e de acesso aos serviços. Deste condicionamento, as formas de nascimento, adoecimento e mortalidade, com ênfase na saúde materno-infantil, têm maior prevalência na projeção dos diferenciais das desigualdades regionais e de classe, resultantes dos processos de industrialização e urbanização. Pelas lentes da CNDSS e com esteio na PNAD, observa-se a redução das desigualdades sociais, com manutenção de outras.

A renda oriunda do trabalho, segundo o Índice de Gini, teve sua concentração pouco reduzida: de 0,57 em 2003, para 0,54 em 2007, no curso do "extraordinário aumento da riqueza" pela elevação do produto interno bruto (PIB), de 2.060 
dólares para 5.250. Outros estudos informam que os diferenciais entre ricos e pobres são ainda consideravelmente elevados, devido à redução aferida ter sido procedida em função da renda oriunda do trabalho e não da renda do capital. As tendências com relação a renda, escolaridade e saúde apontadas são componentes do Índice de Desenvolvimento Humano (IDH), da Organização das Nações Unidas, segundo o qual o país passou de 0,649 em 1975, para 0,800 em 2005. Evidenciam-se mudanças positivas na educação, com redução da população analfabeta dos 56\% em 1940, para 12,3\% em 2006, mantidas as disparidades nas desigualdades regionais de $22 \%$ no Nordeste, contra 7,6\% no Sul. Essa relação varia de $17,9 \%$, dentre os maiores de 15 anos, em até $1,3 \%$ para os de renda per capita superior a dois salários mínimos.

A associação da estratificação social está cunhada, nos diferenciais em saúde, segundo renda, escolaridade, gênero, cor da pele e local de moradia com a situação de saúde. Estas variáveis têm atenuantes no acesso da atenção básica a exames preventivos para câncer de mama e de colo de útero, consultas de pré-natal, em nítidos gradientes. Dado expressivo da redução das desigualdades em saúde é a queda dos indicadores das formas graves de desnutrição, em relação a estudos anteriores de avaliação nutricional de população. A prevalência é ainda elevada, em comparação aos níveis internacionais e população avaliada beneficiária dos programas sociais. Os 3,8 milhões de pessoas com déficit de peso e 38,8 milhões com excesso não constituem paradoxo ou melhoria da situação nutricional.

A rigor, o padrão de classificação nutricional utilizado na Chamada Nutricional 2005 pode reduzir em até duas vezes os percentuais de achados com grave desnutrição. Como exemplo, o déficit na relação dos indicadores peso $\mathrm{x}$ idade, comparado ao padrão de avaliação mais sensível e internacionalmente aceito, o do Nutrition Center Health and Science (NCHS) de Harvard. Pelo instrumento utilizado, houve manutenção de elevada prevalência dos indicadores de cronicidade na relação altura x idade. Achados que projetam nosso entendimento sobre transição nutricional em padrão que agrega distintas etiologias da obesidade: a de ricos e de pobres. Neste prisma, se faz pertinente distinguir a sutileza da aparente melhoria da situação nutricional, cujo padrão transitou em complexidade. Com a elevação do consumo de calorias oriundas de alimentos de baixo valor biológico (farináceos, infusōes, gorduras e açúcares), pelo aumento de poder de compra do salário mínimo e da renda 
distributiva dos programas sociais. Outra é etiologia da obesidade dos ricos, determinada pelo consumo excessivo de proteínas, gorduras e açúcares, de alto valor biológico e de custo.

Conceitualmente, o saneamento básico consiste nos cuidados com o ciclo completo da água: sua distribuição, tratamento, esgotamento e destino final dos resíduos sólidos. No texto em apreço, os descritores são de elevação da média nacional de distribuição formal de água de $80 \%$ para $83 \%$, e de esgotamento adequado de $65 \%$ a $70 \%$ para os domicílios permanentes. Esses dados mascaram os gaps regionais, que atingem até $70 \%$ nas regiōes Norte e Nordeste. A correlação das condições de emprego e trabalho com os problemas de saúde dos trabalhadores por renda e região está demarcada na extensão das desigualdades combinadas pelo desenvolvimento.

As doenças ocupacionais evitáveis elencadas são a silicose, as pneumoconioses e envenenamento (com chumbo e a asbestose), aliadas ao estresse da condição pós-moderna, aos sintomas e às desordens mentais. Os processos de trabalho de exposição contínua aos perigos químicos e físicos associados ao estresse e fatores psicossociais, desencadeadores das lesōes por esforço repetitivo, também tiveram suas taxas de prevalência elevadas; da mesma forma, as doenças respiratórias e neoplásicas, pela crescente poluição ambiental resultante da desordem urbano-industrial.

Em relação ao acesso a serviços de saúde, o traçado empírico dessa obra revela que os princípios de universalidade e equidade do SUS estão distantes de serem alcançados. Nas desigualdades regionais de oferta e qualidade, em todos os níveis, a equidade está subvertida na medida em que os de maior renda e nível de escolaridade têm $60 \%$ a mais de sucesso em suas demandas ao setor da saúde pública. Os autores assinalam que países com esta realidade têm como agravantes: o "desgaste do capital social, que impacta negativamente na situação de saúde", fragilidade na definição e regulação de políticas públicas, nos laços de coesão social resultantes dessas formas de iniquidade. Asseveram que são exatamente esses países os que "menos investem nesse capital e no capital humano".

O panorama da situação de saúde também foi avaliado entre os diversos grupos sociais, segundo comportamentos e estilos de vida, com base em revisão de literatura sobre dieta, exercício físico, tabagismo e alcoolismo. Nessa dimensão comportamental, estão corroborados marcadores que relacionam a melhoria da 
renda com o aumento de exercício físico e consumo de vegetais. Em contraponto, ocorre menor redução nos indicadores de saúde com relação à baixa renda com escolaridade em mulheres, e no tabagismo e alcoolismo, que se elevaram.

Neste prisma, entendemos que as desigualdades sociais, aliadas à retração da estrutura social em todos os níveis da assistência, moldaram a complexidade da situação de saúde na conjuntura avaliada. O perfil epidemiológico transitou na combinação de velhas e novas formas do adoecimento e de morte, com a junção de distintas etiologias do atraso e da modernidade, com demanda de processos no cuidado pela elevação da morbi-mortalidade de doenças diarreicas, nutricionais, neoplásicas, cardiológicas, cerebrovasculares e as externas ao setor: violência doméstica e do trânsito. Nesta ordem, para melhor alcance da universalização, integralidade e equanimidade da assistência no sistema público, são requeridos maiores percentuais de recursos.

A melhoria na redução das taxas de natalidade, da desnutrição grave, de mortalidade infantil e geral, e na elevação da esperança de vida, tem nuances de efetividade que devem ser atribuídas, além do setor saúde, às ações transversais. A sinergia produzida pelas ações intersetoriais das redes sociais em sua extensão de cobertura de distribuição, de tratamento da água e de terapias simplificadas na convergência das ações básicas, de forma transversal, aproxima a integralidade nessa assistência. A redução dessa taxa não reflete necessariamente melhoria nas condições de vida a ponto de, atualmente, a mortalidade infantil não mais se constituir em indicador de pobreza e minimizar o IDH como avaliador de redução de desigualdades, devido aos distintos métodos empregados na avaliação da renda e agregação de dados escolares.

As políticas e programas em curso foram avaliados na focalização das distintas redes sociais e setoriais que atuam sobre tradicionais paradigmas da assistência à saúde materno-infantil. O histórico da assistência social demarca a teoria do capital humano como norteadora dessa assistência, com ênfase em países de desenvolvimento desigual, distâncias sociais extremadas e atraso na cultura política. Em decorrência da retração no financiamento das políticas sociais nas décadas perdidas pelo avanço do programa da globalização, ou mundialização financeira, a seletividade foi reforçada por arranjos organizacionais da assistência à saúde com hierarquização da condição humana, ao tratar verticalmente os social e horizontalmente iguais. Nessa lógica é que se explica a predominância 
de atenção básica minimalista dirigida a grupos de risco biológico. A elevação

da morbimortalidade infantil indígena, nos últimos cinco anos, teve apelo de maiores atenções da assistência.

Os descritores de saúde utilizados para esse grupo repetem a maximização pela renda e escolaridade da mãe - com a atenção pré-natal, parto, crescimento uterino, peso ao nascer, amamentação, cobertura vacinal - na redução da mortalidade infantil em menores de cinco anos, entre 1990 e 2005. Em média, esta taxa, que era de 53,7 óbitos para cada mil nascidos vivos, foi reduzida para $28,8 \%$ - com decréscimo de 46,4\%. O declínio ocorrido também comprova a boa correlação dessas variáveis sociais da mãe com a duração de aleitamento materno exclusivo e o consumo cognitivo de nutrientes. Os indicadores negativos listados para as mães de renda superior são os de elevação de parto por cesarianas, sobrepeso/obesidade e uso de terapia de reidratação oral em episódios de diarreia.

Para esse mesmo grupo, a mortalidade infantil indígena de 51,4 é extremamente superior, inclusive em relação às de cor/raça "pretas e pardas", que é de 34,9 e 33,0, respectivamente. As taxas de escolaridade, habitação, saneamento básico, consumo de nutrientes essenciais e cobertura e qualidade dos serviços de saúde determinam a deterioração progressiva da situação nutricional e de saúde, expressivamente na prevalência de doenças diarreicas e respiratórias, pela nulidade das condições materiais listadas. Em paródia, adoecem e morrem mesmo é de fome endêmica que se agrava pelos vetores veiculados pela água e pela nulidade ou precariedade da assistência.

A seção de recomendações às intervenções se constitui de teses propositivas às políticas e programas em curso, aos arranjos inter-setoriais e à institucionalização de processos de promoção que possibilitem equidade nas redes sociais de assistência à saúde. Os autores advertem que suas recomendações se destinam à superação de problemas assinalados em relatório, referentes às iniquidades em saúde, horizonte dessa comissão. Superando os limites dessa seção, apresenta-se extensa e atualizada lista de referências, além de bibliografia complementar. No mapeamento dessa dimensão, foram entrelaçadas as políticas sociais que têm relação com os determinantes sociais da saúde e da atenção interinstitucional. A execução orçamentária verificada sobre essas políticas foi nas açōes consideradas como de possibilidades e potencialidades de articulação com o setor e de impacto na situação de saúde. 
Nesse entrelaçamento, os autores afirmam que "os valores e volume de ações envolvidas indicam que o conjunto temático ocupa lugar de destaque na agenda política e que o crescimento dos valores envolvidos indica que não houve, de maneira geral, depreciação nos níveis de investimento no setor”. Em relação às políticas, programas e ações, os achados refletem baixa desarticulação da temática entre os órgãos executores com o Ministério da Saúde, fragmentação das ações com provável redundância e concorrência em todos os níveis. Mesmo com o caráter descritivo da revisão efetuada, foi possível a leitura de implicações que tal desarticulação induz às políticas públicas. Para tal reversão, sugerem ampliar o patamar de investimento das ações estudadas e a racionalização de arranjos institucionais que sistematizem, articulem e executem ações em todos os níveis federativos, enfatizando as de maior consistência numa agenda comum que se destine a reverter os determinantes sociais da saúde.

A CNDSS recomenda que a institucionalização de processos de intervenção aos determinantes sociais em saúde deve contemplar os distintos níveis de promoção à equidade, nos termos das dimensóes distais e proximais do modelo de Dahigren e Whitead, permeados pelos intermediários, com foco na intersetorialidade, participação social e evidências científicas. Essa instância deve ser coordenada pela Casa Civil da Presidência da República, com prioridade para as açôes intersetoriais de promoção da saúde na infância e adolescência, e de fortalecimento das redes sociais. A proposição encoraja a participação social para o empoderamento $e$ priorização de grupos vulneráveis, assim como o fortalecimento dos mecanismos de gestão participativa, através dos Conselhos Municipais de Saúde.

Em síntese, no documento de lançamento da comissão, o discurso buscou recuperar a temática em sua aproximação com a totalidade onde as iniquidades em saúde estão categorizadas como "nossa mais grave doença". Para tal descrição, os autores produziram e utilizaram dados contundentes, com preciosas lentes sobre as políticas analisadas e nos remetem à diversidade de estratégias desenvolvidas no âmbito acadêmico, de eventos, comunicaçôes coordenadas, congressos ou do trabalho sistemático em bibliotecas. Os colaboradores da obra nos brindam com descritos souvenirs de um estigma social que se arrasta dos primeiros estágios econômicos; em tempo, as desigualdades sociais e a urbanização necessária ao escoamento da produção agrícola e das relações internacionais que desencadearam nosso projeto de saúde pública - embrião das políticas sobre o social - portanto, mola na dinâmica do projeto de desenvolvimento nacional. 